\title{
Isolation of Cardiovascular Precursor Cells from the Human Fetal Heart
}

\author{
Christine Gonzales, Ph.D., ${ }^{1}$ Nina D. Ullrich, Ph.D., ${ }^{2}$ Stefan Gerber, M.D., ${ }^{3}$ \\ Corinne Berthonneche, PharmD, Ph.D., ${ }^{4}$ Ernst Niggli, Ph.D., ${ }^{2}$ and Thierry Pedrazzini, Ph.D. ${ }^{1}$
}

Weakening of cardiac function in patients with heart failure results from a loss of cardiomyocytes in the damaged heart. Cell replacement therapies as a way to induce myocardial regeneration in humans could represent attractive alternatives to classical drug-based approaches. However, a suitable source of precursor cells, which could produce a functional myocardium after transplantation, remains to be identified. In the present study, we isolated cardiovascular precursor cells from ventricles of human fetal hearts at 12 weeks of gestation. These cells expressed Nkx2.5 but not late cardiac markers such as $\alpha$-actinin and troponin I. In addition, proliferating cells expressed the mesenchymal stem cell markers CD73, CD90, and CD105. Evidence for functional cardiogenic differentiation in vitro was demonstrated by the upregulation of cardiac gene expression as well as the appearance of cells with organized sarcomeric structures. Importantly, differentiated cells presented spontaneous and triggered calcium signals. Differentiation into smooth muscle cells was also detected. In contrast, precursor cells did not produce endothelial cells. The engraftment and differentiation capacity of green fluorescent protein (GFP)-labeled cardiac precursor cells were then tested in vivo after transfer into the heart of immunodeficient severe combined immunodeficient mice. Engrafted human cells were readily detected in the mouse myocardium. These cells retained their cardiac commitment and differentiated into $\alpha$-actinin-positive cardiomyocytes. Expression of connexin- 43 at the interface between GFP-labeled and endogenous cardiomyocytes indicated that precursor-derived cells connected to the mouse myocardium. Together, these results suggest that human ventricular nonmyocyte cells isolated from fetal hearts represent a suitable source of precursors for cell replacement therapies.

\section{Introduction}

$\mathbf{H}$ EART FAILURE, which develops after myocardial infarction or chronic hypertension, remains a major cause of morbidity and mortality in developed countries. In the damaged heart, weakening of cardiac function is essentially due to a massive loss of cardiomyocytes. Ultimately, cardiac transplantation remains the only therapeutic option for endstage heart failure. However, the low number of organ donors and the side effects of immunosuppressive drugs limit the access to a transplantation program to a few thousands of patients a year. In this context, cell replacement therapies could represent attractive alternative approaches. Cardiac precursor cells (CPCs) could be transferred in the damaged heart to produce new cardiomyocytes and recreate a myocardium to restore cardiac function. ${ }^{1,2}$

In the classical view, cardiomyocytes are considered as terminally differentiated cells that adapt to increased work- load exclusively through hypertrophy. However, recent observations indicate that cardiomyocytes could be replaced continually in the heart through a process involving differentiation, maturation, senescence, and death. ${ }^{3,4}$ The discovery of resident cells with stem cell characteristics in adult tissues suggests that the heart demonstrates some regenerative potential. Nevertheless, CPCs cannot be easily recognized as no specific markers are currently available. Therefore, surrogate markers, which are expressed on the surface of hematopoietic stem cells, have been used to identify CPCs in the heart. In the mouse, resident stem cells have been isolated from the postnatal myocardium depending on the expression of at least one of the following markers: the stem cell factor receptor c-kit ${ }^{5}$ or the stem cell antigen (Sca)-1. ${ }^{6}$ In addition, the ATP-binding cassette transporter ABCG2 identifies a population of cardiac precursors based on its capacity to efflux Hoechst dye..$^{7-9}$ To produce a functional myocardium, CPCs must give rise to

\footnotetext{
${ }^{1}$ Experimental Cardiology Unit, Department of Medicine, University of Lausanne Medical School, Lausanne, Switzerland.

${ }^{2}$ Department of Physiology, University of Bern, Bern, Switzerland.

${ }^{3}$ Department of Gynecology and Obstetrics, University of Lausanne Medical School, Lausanne, Switzerland.

${ }^{4}$ Cardiovascular Assessment Facility, University of Lausanne Medical School, Lausanne, Switzerland.
} 
several different muscle and nonmuscle cell types, specifically cardiomyocytes, endothelial cells, and smooth muscle cells (SMCs) ${ }^{10}$ Using a transgenic approach to trace the fate of progenitors in the heart, $\mathrm{Nkx} 2.5^{\mathrm{POS}}$ cells were shown to give rise to cardiac cells and SMCs. ${ }^{11}$ Similarly, multipotent cardiovascular progenitors expressing the Lin-1, Isl-1, Mec-3domain transcription factor Islet (Isl)-1 have been described in the developing heart. Therefore, Isl1 ${ }^{\mathrm{POS}} \mathrm{Nkx} 2.5^{\mathrm{POS}}$ cardiac progenitors, also expressing the vascular endothelial growth factor receptor-2 known as Flk1 in the mouse and KDR in humans, were shown to produce the three main cardiac lineages (cardiomyocytes, endothelial cells, and SMCs). ${ }^{12-14}$ Along these lines, mesodermal progenitors expressing Flk1 were demonstrated to contribute to both cardiac and skeletal muscle development. ${ }^{15,16}$ Cardiogenic differentiation has also been studied using mouse embryonic stem (ES) cells. Multipotent cardiovascular progenitors derived from ES cells express mesodermal markers such as Flk1 and then Isl1. ${ }^{17,18}$ Moreover, cardiovascular progenitors giving rise to the three lineages have also been derived from c-kit ${ }^{N E G}, K^{2} R^{L O W}$ human ES cells. ${ }^{19}$ Finally, bone morphogenetic protein-2-treated human ES cells were shown to express the stage-specific embryonic antigen (SSEA)-1 and then the mesodermal marker brachyury and to commit to the cardiogenic lineage. ${ }^{20}$ This is reminiscent of what has been observed in multipotent cardiovascular progenitors isolated from the neonatal and adult rat hearts based on SSEA-1 expression. ${ }^{21}$ Whether undifferentiated cardiac cells expressing these different markers represent distinct CPCs subpopulations remains unclear. Nevertheless, it is usually agreed that coexpression of a stem cell marker and an early cardiac gene such as Nkx2.5 represents a signature of CPCs.

Over the past years, adult stem cells from several different sources have been assayed for their capacity to generate myocardial tissue after transfer into the injured heart. These sources include unfractioned bone marrow cells, bone marrowderived mononuclear cells, bone marrow mesenchymal stem cells, hematopoietic stem cells, circulating endothelial progenitor cells, and skeletal myoblasts. Results from these studies did not unambiguously demonstrate a clinical benefit of the transferred cells, suggesting that the functional improvement of the failing heart following stem cell transplantation will not be easily achieved. In this context, the use of mesodermal progenitors or even precursor cells isolated from the heart itself could facilitate the cardiogenic differentiation of these undifferentiated cells. Indeed, CPCs isolated from the heart may be more effective in generating new myocardium than progenitor cells from other organs, because they might be already committed to the different cardiovascular lineages. $5,6,9,11,12,14,21-27$ For instance, CPCs have been shown to differentiate into cardiomyocytes and to improve cardiac function in rodent models of myocardial infarction. ${ }^{5,21-25}$ Recent publications described human cardiac precursors isolated from the fetal heart based on the capacity of antibodies directed against the mouse Sca-1 protein to bind to an unknown human cell surface protein. Under differentiation conditions, these precursors gave rise to cardiomyocytes, SMCs, and endothelial cells in vitro and in vivo when injected into mice myocardium. ${ }^{27-29}$

In humans, the heart already begins to beat at stage 10 (roughly 28 days of development). Separation of atrial and ventricular myocardium starts at 7 weeks of development and is completed around the 12th week of development. At this stage, the four-chamber heart is formed..$^{30}$ In this report, we decided to investigate whether the human fetal heart represents an appropriate source of human cardiac precursors for cell replacement therapies. Heart tissues from healthy Caucasian fetuses were obtained following voluntary abortion at 12 weeks of gestation. Proliferating Nkx2.5 ${ }^{\mathrm{POS}} \alpha$-actinin ${ }^{\mathrm{NEG}}$ CPCs were readily isolated and maintained during several passages in vitro. The vast majority of these cells expressed Nkx2.5 but not Sca1, Isl1, or KDR. We then demonstrated the capacity of these precursors to differentiate into cardiomyocytes and SMCs. Moreover, CPCs were able to engraft into immunodeficient mouse heart, to retain their cardiogenic commitment, and to produce a fully differentiated progeny.

\section{Materials and Methods}

\section{Primary cell cultures}

Human fetal hearts were collected from donation after voluntary termination of pregnancy at 12 weeks of gestation. The protocol received the authorization of the Hospital Ethical Committee. Ventricles were mechanically minced prior to enzymatic digestion in buffer containing $0.45 \mathrm{mg} / \mathrm{mL}$ collagenase (Worthington Biochemical Corp.) and $1 \mathrm{mg} / \mathrm{mL}$ pancreatin (Invitrogen) (Fig. 5A). The cell population that adhered in less than $24 \mathrm{~h}$ was named CPCs and cells that remained in suspension after $24 \mathrm{~h}$ were discarded. Adherent cells were expanded in culture in proliferation medium, a 3:1 mixture of DMEM $1 \mathrm{~g} / \mathrm{L}$ glucose and Medium 199 (Invitrogen) supplemented with $10 \%$ Horse serum (Serotec), $5 \%$ fetal bovine serum (Serotec), $100 \mathrm{U} / \mathrm{mL}$ penicillin (Invitrogen), and $100 \mu \mathrm{g} / \mathrm{mL}$ streptomycin (Invitrogen). After three passages, cells were switched to a serum-free differentiation medium. Differentiation medium contained MEM alpha (Invitrogen) supplemented with $1 \mu \mathrm{M}$ dexamethasone (Sigma-Aldrich), $50 \mu \mathrm{g} / \mathrm{mL}$ ascorbic acid (Sigma-Aldrich), $10 \mathrm{mM} \beta$-glycerophosphate (Sigma-Aldrich), $100 \mathrm{U} / \mathrm{mL}$ penicillin (Invitrogen), and $100 \mu \mathrm{g} / \mathrm{mL}$ streptomycin (Invitrogen) and has been described elsewhere. ${ }^{26}$

\section{Analysis of differentiation marker expression by immunofluorescence, reverse transcriptase- polymerase chain reaction, real-time polymerase chain reaction, and flow cytometry}

The different markers used in this study are listed in Supplementary Table S1 (Supplementary Data are available online at www.liebertonline.com/tea). For detailed description of the protocol, see Supplementary Data.

\section{Confocal calcium imaging}

Cells were grown on gelatin-coated glass coverslips and loaded with the fluorescent $\mathrm{Ca}^{2+}$ indicator fluo-3 by exposure to fluo-3-AM (Biotium, $5 \mu \mathrm{M}, 25 \mathrm{~min}, 10 \mathrm{~min}$ de-esterification). $\mathrm{Ca}^{2+}$ imaging was performed on a laser-scanning confocal microscope (Micro-Radiance, Bio-Rad) with a $40 \times$ oilimmersion objective. Fluo-3 was excited at $488 \mathrm{~nm}$ with an argon ion laser, and emitted fluorescence was collected above $500 \mathrm{~nm}$. Linescan images were recorded at a rate of 50 lines/s. In field-stimulated cells, $\mathrm{Ca}^{2+}$ release events were elicited by electrical stimulation with a custom-built field stimulator. Triggering pulses were $2.5 \mathrm{~m}$ long with an amplitude of $1.5 \times$ above threshold voltage (between 20 and $40 \mathrm{~V}$ ). Different 
FIG. 1. Characterization of CPCs after three passages in proliferation medium. (A) Experimental cell isolation schema. (B) Bright-field image of human CPCs in culture in proliferation condition. (C) RT-PCR of early cardiac markers (Gata4, Nkx2.5, Isl1, Mef2c), late cardiac markers $(\alpha-\mathrm{MHC}, \beta-$ MHC, cardiac troponin I), $\mathrm{Cx}-43$, and GAPDH as a loading control in the human fetal heart at 12 weeks of gestation (fetal heart) and in the isolated cells (CPCs in proliferation). (D) Quantitative real-time RT-PCR of the cardiac markers $\alpha$-MHC, $\beta$ $\mathrm{MHC}$, and cardiac troponin I of the isolated cells relative to the human fetal heart at 12 weeks of gestation. White bars: fetal heart; black bars:

A

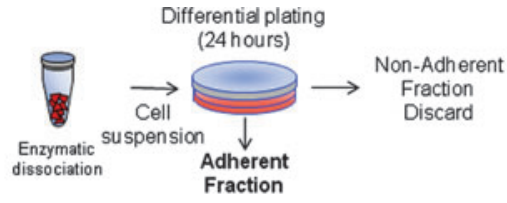

C
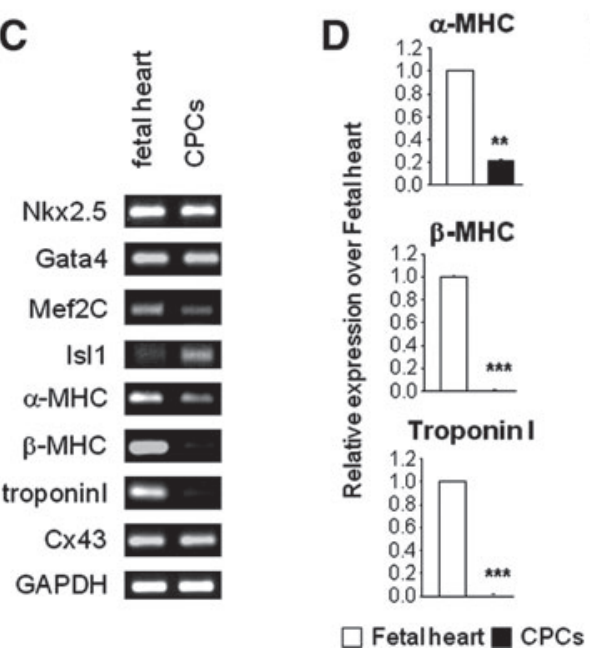

B

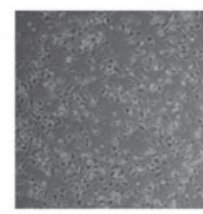

E

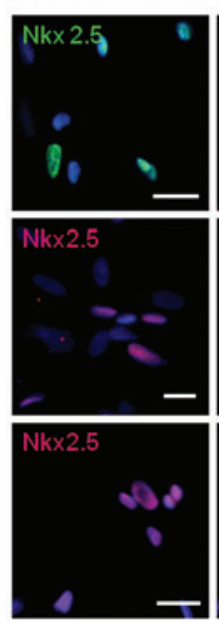

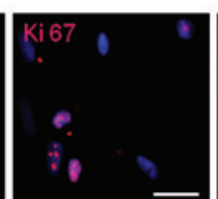

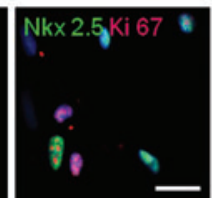

KDR



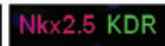

Nkx2.5 KDR CPCs. (E) Staining of the cells. Upper rows represent costaining for Nkx2.5 (green) and Ki67 (red). Middle rows stained for Nkx2.5 (red) and KDR (green). Lower rows correspond to Nkx2.5 (red) and Isl1 (green); white arrowhead indicates double-stained cells. Nuclei were stained with DAPI (blue). Scale bars: $25 \mu \mathrm{m}$. The bars in $\mathbf{D}$ represent means \pm SD. Asterisks denote significant difference compared with expansion medium $\left({ }^{* *} p<0.01\right.$; $\left.{ }^{* * *} p<0.001\right)$. CPCs, cardiac precursor cells; RT-PCR, reverse transcriptasepolymerase chain reaction; MHC, myosin heavy chain; Cx, connexin; GAPDH, glyceraldehyde 3-phosphate dehydrogenase; SD, standard deviation; DAPI, 4',6'-diamidino-2'-phenylindole.

pacing frequencies between 0.1 and $1 \mathrm{~Hz}$ were tested. Changes in intracellular $\mathrm{Ca}^{2+}$ during electrical pacing were recorded in linescan images. Extracellular solution contained (in $\mathrm{mM}) 140 \mathrm{NaCl}, 5.4 \mathrm{KCl}, 2 \mathrm{CaCl}_{2}, 1.1 \mathrm{MgCl}_{2}, 5 \mathrm{HEPES}$, and 10 glucose $(\mathrm{pH} 7.4)$. Confocal images were analyzed in ImageSXM and further processed using IgorPro. Changes in cytosolic $\mathrm{Ca}^{2+}$ levels are expressed as changes in fluorescence $\left(\Delta F / F_{0}\right)$.

\section{Vector production and genetic labeling of cells}

For detailed protocol, see Supplementary Data.

\section{Experiments in vivo}

To avoid rejection of transplanted human cells, immunodeficient mice were used (S/B6.CB17-PrKdc scid Ma SN1913; The Jackson Laboratory). All animal procedures were approved by the Animal Ethics Committee. Mice were maintained under specific pathogen-free condition. Severe combined immunodeficient (SCID) mice ( 9 weeks old) were operated under general anesthesia with isoflurane (Baxter Healthcare SA). Analgesia was performed with $0.1 \mathrm{mg} / \mathrm{kg}$ subcutaneous injection of Temgesic (buprenorphine; Essex Chemie AG). The heart was exposed through a left thoracotomy and three injections of a suspension of green fluorescent protein (GFP)-labeled single cells were performed in the myocardium, in the left ventricle. Each injection contained $3.3 \times 10^{5}$ cells suspended in $10 \mu \mathrm{L}$ of $0.09 \% \mathrm{NaCl}$. Control animals received injections of $10 \mu \mathrm{L}$ of $0.09 \% \mathrm{NaCl}$. Two groups of mice were sacrificed either at 1 or 4 weeks after injection. Hearts were collected and then embedded in optimal cutting temperature for heart sectioning. Immunostaining for GFP, connexin 43 (Cx43), and either Nkx2.5 or $\alpha$-actinin was performed.

\section{Statistical analysis}

Analysis of the significance between different groups was performed using Student's t-test and one-way analysis of variance.

\section{Results}

\section{Isolation of cardiovascular precursors from the fetal heart}

Human fetal ventricles were isolated, minced, digested, and processed into primary cultures (Fig. 1A). The cell population that adhered in less than $24 \mathrm{~h}$ represents the nonmyocyte population containing CPCs (Fig. 1B). These cells were passaged several times and can be kept frozen. To characterize the cells, reverse transcriptase-polymerase chain reaction (RT-PCR), quantitative real-time RT-PCR, immunostaining, and flow cytometry were performed after three passages in proliferation medium. Under these conditions, proliferating cells expressed the early cardiac transcription factors Nkx2.5, Gata4, Mef2C, and Isl1 (Fig. $1 C)$. The late cardiac marker $\beta$-myosin heavy chain $(\beta$ $\mathrm{MHC}$ ) and cardiac troponin I were not expressed, whereas some weak expression of $\alpha$-MHC was detected. Cells also expressed Cx43, a protein known to be expressed by differentiated cardiomyocytes and by mesenchymal stem 

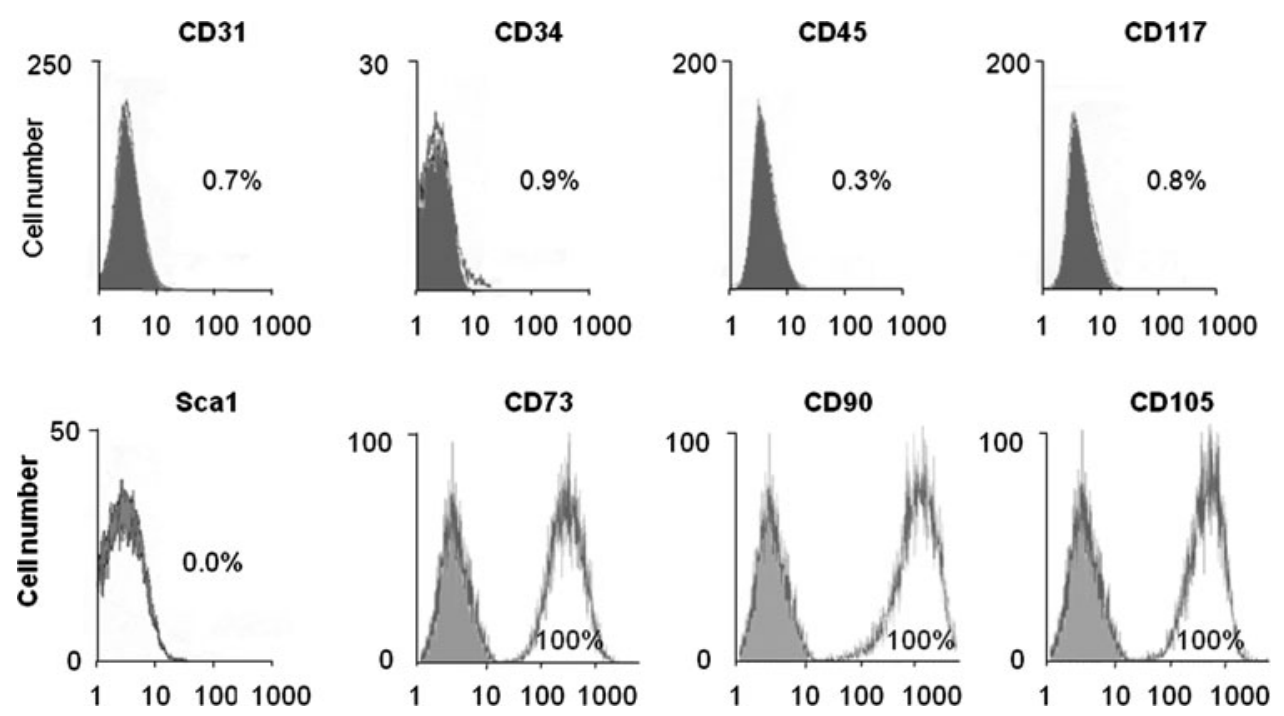

FIG. 2. Flow cytometry profiles of CPCs after three passages in proliferation medium. Flow cytometric analysis of CD31, CD34, CD45, CD117, CD73, CD90, and CD105 of cultured CPCs after three passages in expansion medium. Histogram plots are shown with the isotype control in gray and the specific signal in white.

cells. Compared with fetal ventricles at 12 weeks of gestation, the expression levels of $\alpha-\mathrm{MHC}$ in proliferating CPCs were significantly lower than that found in the human fetal heart (Fig. 1D). By immunostaining, Nkx2.5 expression was detected in a majority of cultured cells ( $>60 \%)$. Nkx2.5 ${ }^{\mathrm{POS}}$ cells also expressed the proliferation marker Ki67 (Fig. 1E). Among the Nkx2.5 ${ }^{\mathrm{POS}}$ population, cells expressed very occasionally KDR or Isl1 ( $<1 \%)$. CPCs contained no cells expressing either CD45, CD34, CD31, ckit, or Sca-1 (Fig. 2). As human cells do not express Sca-1, no staining against the mouse Sca-1 antigen was detected by flow cytometry (Fig. 2). In contrast, all cells expressed the mesenchymal markers CD73, CD90, and CD105 (Fig. 2). To evaluate whether a population of cells expressing a pattern of cardiac genes similar to that of the isolated cells could be detected in the human heart at 12 weeks of gestation, we performed a series of immunohistological analyses (Supplementary Data). In the ventricles, a majority of the $\alpha$-actininpositive cardiomyocytes express the transcription factor Nkx2.5 (Supplementary Fig. S1A, a-c). Both Nkx2.5 ${ }^{\mathrm{POS}}$ and $\mathrm{Nkx} 2.5^{\mathrm{NEG}}$ cardiomyocytes demonstrated organized sarcomeric structures (Supplementary Fig. S1B). Endothelial cells and SMCs were identified in small blood vessels using the specific markers CD31 (PECAM-1) and smooth muscle-specific myosin heavy chain (smMHC) (Supplementary Fig. S2A). No smMHC ${ }^{\mathrm{POS}}$ cells expressed $\alpha$-actinin (Supplementary Fig. S2B) or Nkx2.5 (Supplementary Fig. S2C). KDR staining was detected in capillary-like structures throughout the ventricles (Supplementary Fig. S3). No cells coexpressed KDR and Nkx2.5 in ventricles (Supplementary Fig. S3). Large vessels of the outflow tract (aorta and pulmonary arteries) were also revealed by antibodies directed against smMHC, $\alpha$-smooth muscle actin (SMA), and CD31 (Supplementary Fig. S4). Immunostaining of successive heart sections identified clusters of Isl1 ${ }^{\mathrm{POS}}$ cells in the area of the aorta and the pulmonary artery (Supplementary Fig. S4A, a and b). These cells did not express $\alpha$-actinin (Supplementary Fig. S4A, a and b) or Nkx2.5 (Supplementary Fig. S5A). In contrast, groups of $\mathrm{Nk} \times 2.5^{\mathrm{POS}}, \alpha-$ actinin $^{\text {NEG }}$ cells were found at the interface between the atrioventricular ring and the ventricles (Supplementary Fig. S4A, c). Some of these cells expressed KDR (Supplementary
Fig. S5B). Most of the cells detected in the ventricles were $\alpha$ actinin $^{\mathrm{POS}}$ and $\mathrm{Nkx} 2.5^{\mathrm{POS}}$.

\section{Cardiogenic differentiation in vitro}

Cardiogenic differentiation was induced by switching the cells to differentiation medium, which was previously shown to promote cardiogenic commitment in cardiac precursors isolated from the neonatal heart. ${ }^{26}$ Gene expression of cardiac genes Nkx2.5, troponin I, $\alpha-\mathrm{MHC}$, and $\beta-\mathrm{MHC}$ was increased in cells stimulated for 1 week in differentiation medium compared with cells in expansion conditions (Fig. 3A). We then performed immunostaining to detect $\alpha$-actinin ${ }^{\mathrm{POS}}$ and $\mathrm{Nkx2.5^{ \textrm {POS } }}$ cells. Based on the expression of these two markers, we identified different types of $\alpha$ actinin $^{\text {POS }}$ cells (Fig. 3B). A small population was characterized by diffuse $\alpha$-actinin staining and $\mathrm{Nkx} 2.5$ expression ( $<5 \%$; Fig. 3B, upper row), whereas a vast majority of $\alpha$-actinin-stained cells demonstrated organized sarcomeres. Among this group, most of the cells expressed also Nkx2.5 (Fig. 3B, middle row) and only a few cells were $\mathrm{Nkx2.5}$ negative $(<1 \%$; Fig. $3 \mathrm{~B}$, lower row). A small percentage of cardiomyocytes was detected by $\alpha$-actinin immunostaining after three passages under proliferation conditions, representing spontaneous differentiation (1.45\%; Fig. 3B). In contrast, $\alpha$-actinin $^{\mathrm{POS}}$ cells represented $20 \%$ of the total cell number after induction of differentiation (Fig. 3C). As cardiac precursors appeared to express mesenchymal markers, we evaluated whether these surface proteins could be used to isolate a subset containing cardiac precursors from proliferating bulk cultures using fluorescence-activated cell sorting (FACS). Therefore, early-passage cells were stained with antibodies directed against CD73, CD90, and CD105, sorted, and induced to differentiate into cardiomyocytes. Approximately $80 \%-90 \%$ of the cells were positive for the three markers (Supplementary Fig. S6A-C). Control of expression after sorting showed that all isolated cells expressed CD73, CD90, and CD105 (not shown). Then, 1 week after induction, cardiogenic differentiation was readily demonstrated by increased late cardiac marker expression ( $\alpha$-MHC, $\beta-\mathrm{MHC}$, cardiac actin; Supplementary Fig. S6C) and by immunostaining (Nkx2.5, $\alpha$-actinin; Supplementary Fig. S6D). 
FIG. 3. Differentiation of CPCs into cardiomyocytes in vitro. (A) Quantitative realtime RT-PCR analysis of $\alpha$ MHC, $\beta-M H C$, cardiac troponin I, and Nkx2.5 expression in CPCs. Expression in differentiation medium was compared with expansion medium. Black bars: cells in expansion medium; white bars: cells in differentiation medium. (B) Costaining for $\alpha$-actinin (red), Nkx2.5 (green), and nuclei (DAPI in blue). Scale bars: $25 \mu \mathrm{m}$. (C) Quantification of the number of cardiomyocytes ( $\alpha$-acti$\operatorname{nin}^{\mathrm{POS}}$ cells) in the culture; the three cell types identified were considered for quantification. Data are presented as the percentage of $\alpha$-actinin ${ }^{\text {POS }}$ cells over the total number of cells (DAPI ${ }^{\text {POS }}$ nuclei). The bars in A and $\mathbf{B}$ represent means \pm SD. Asterisks denote significant difference compared with expansion medium $\left({ }^{*} p<0.05 ;{ }^{* * *} p<0.001\right)$.
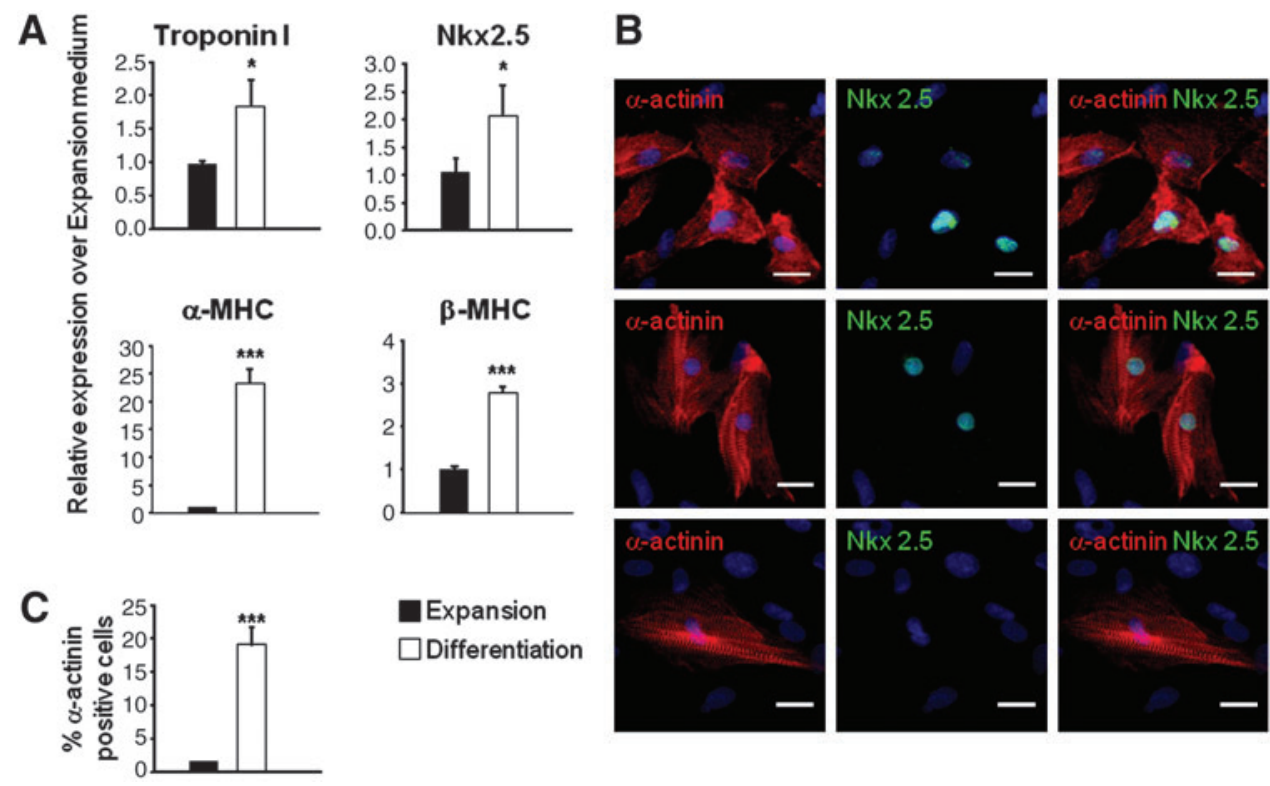

\section{Expansion} $\square$ Differentiation


FIG. 4. $\mathrm{Ca}^{2+}$ signals in $\mathrm{CPC}-$ derived cardiomyocytes. (A) Gene expression analysis of $\mathrm{Ca}_{\mathrm{v}} 1.2, \mathrm{RYR} 2$ and SERCA2b in differentiated CPC-derived cardiomyocytes (quantitative real-time RT-PCR). Black bars: cells in expansion medium; white and gray bars: cells in differentiation medium. (B) Linescan image of spontaneous $\mathrm{Ca}^{2+}$ release events in a population of fluo-3-loaded CPC-derived cardiomyocytes. Details in (a) and (b) show the linescan and line profiles of different forms of $\mathrm{Ca}^{2+}$ signal propagation across the respective cells. (C) Representative recordings of triggered $\mathrm{Ca}^{2+}$ release during electrical stimulation. Cells were field-stimulated at $0.1 \mathrm{~Hz}$. Linescan and global line profile show temporally and spatially synchronized $\mathrm{Ca}^{2+}$ transients across the cell. (D) Detailed view of a global $\mathrm{Ca}^{2+}$ transient during electrical pacing. Three line profiles of different areas within one cell $(\mathrm{a}-\mathrm{c})$ are shown. Note the highly synchronized and rapid onset of $\mathrm{Ca}^{2+}$ release (arrow) despite the variability in peak amplitude and decay of the $\mathrm{Ca}^{2+}$ transient. The bars in $\mathbf{A}$ represent means \pm SD. Asterisks denote significant difference compared with expansion medium $(* * * p<0.001)$.
A
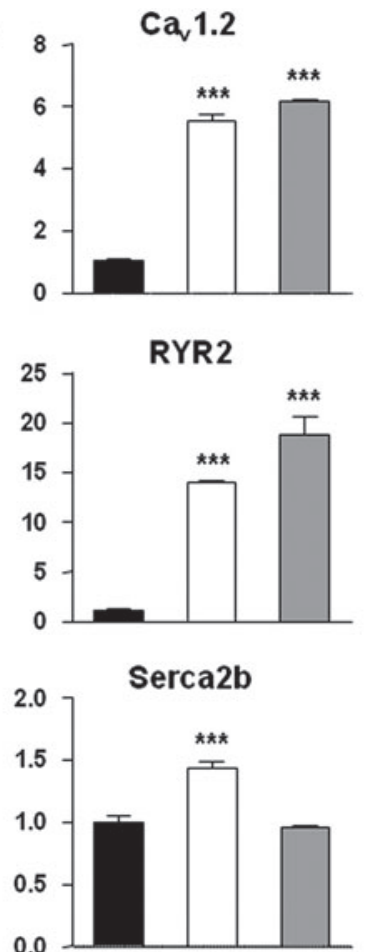

Expansion

Differentiation 1 week Differentiation 2 weeks
B
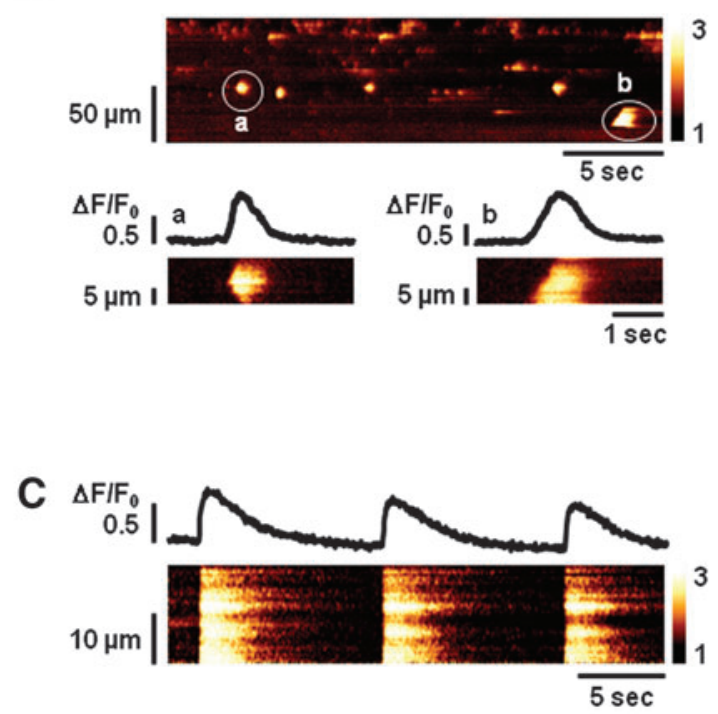

D



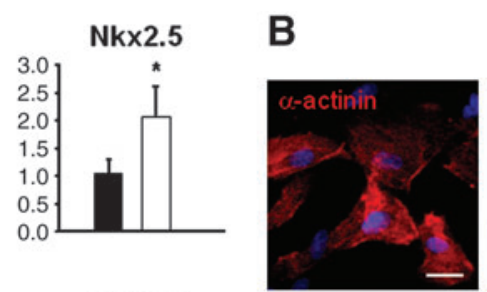


A

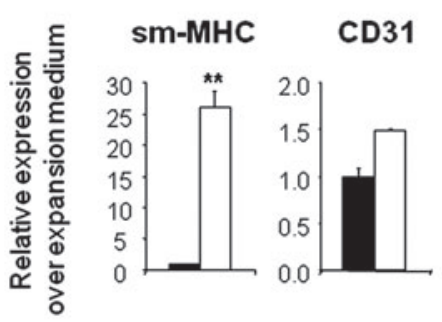

Expansion $\square$ Differentiation

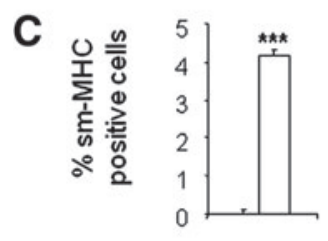

Expansion $\square$ Differentiation
B
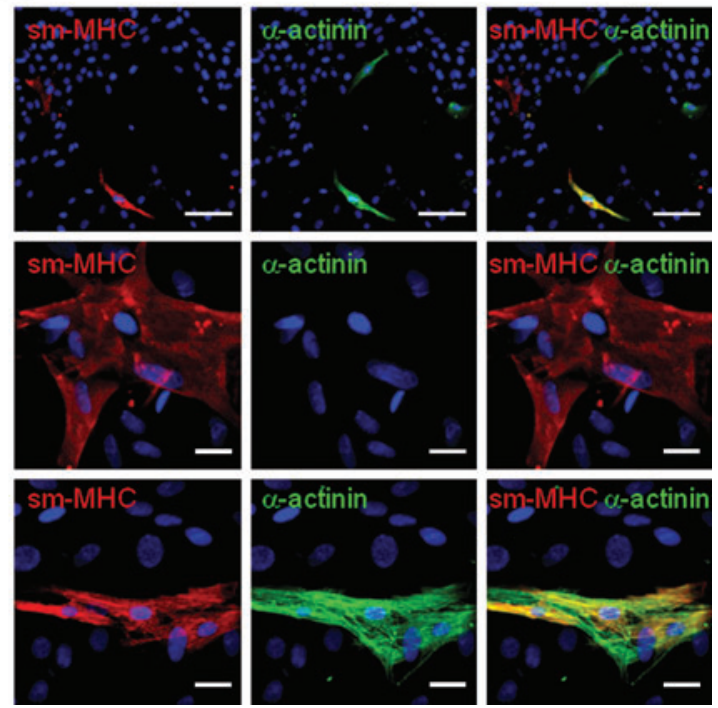

FIG. 5. Differentiation of CPCs into smooth muscle cells and endothelial cells in vitro. (A) Quantitative real-time RTPCR analysis of smMHC and CD31 expression in CPCs. Expression in differentiation medium (black bars) was

compared with expansion medium (white bars). (B) Costaining for smMHC (red), $\alpha$ actinin (red), and nuclei (DAPI in blue). Scale bars in upper rows: $100 \mu \mathrm{m}$; in middle and lower rows: $25 \mu \mathrm{m}$. (C) Quantification of the number of $\mathrm{SMC}\left(\mathrm{smMHC}^{\mathrm{POS}}\right)$ in the culture. Data are presented as the percentage of smMHC ${ }^{\mathrm{POS}}$ cells

over the total number of cells (DAPI ${ }^{\mathrm{POS}}$ nuclei). The bars in A and $\mathbf{C}$ represent means \pm SD. Asterisks denote significant difference compared with expansion medium $\left({ }^{* *} p<0.01 ;{ }^{* * *} p<0.001\right)$. smMHC, smooth muscle-specific myosin heavy chain.

\section{Spontaneous and triggered calcium release events}

To test CPC-derived cardiomyocytes for their cardiogenic functionality and their ability to respond to electrical stimulation, we investigated $\mathrm{Ca}^{2+}$ signaling in resting and in field-stimulated cells (Fig. 4). We first determined whether differentiated cells express L-type calcium channel $\left(\mathrm{Ca}_{\mathrm{v}} 1.2\right)$, ryanodine receptor (RyR2), and sarcoplasmic reticulum calcium ATPase (SERCA2b). Expression of these calciumhandling proteins was stimulated during differentiation (Fig. 4A). Calcium signals were then monitored in undifferentiated and differentiated cells. Cells maintained under proliferation conditions showed no sign of calcium activity (not shown). After 1 week in differentiation medium, a few cells (4\% of tested cells) responded to electrical pacing with $\mathrm{Ca}^{2+}$ transients that were in rhythm with the stimulation frequency, whereas after 2 weeks, cells were highly active in their $\mathrm{Ca}^{2+}$ signaling events $(70 \%$ of tested cells). Depending on their degree of differentiation, CPC-derived cardiomyocytes presented a variety of spontaneous $\mathrm{Ca}^{2+}$ signals. Figure 4B shows a linescan image through a cluster of fluo3-loaded cells at rest. Increase in fluorescence indicates an increase in cytosolic $\mathrm{Ca}^{2+}$ levels at spontaneously active sites. Detailed linescans $a$ and $b$ show different types of spatial and temporal $\mathrm{Ca}^{2+}$ signal propagation in two independent cells. In $a, \mathrm{Ca}^{2+}$ rise starts in the center of the cell and propagates into both directions before release stops. In $b, \mathrm{Ca}^{2+}$ release starts on one end of the cell and spreads in
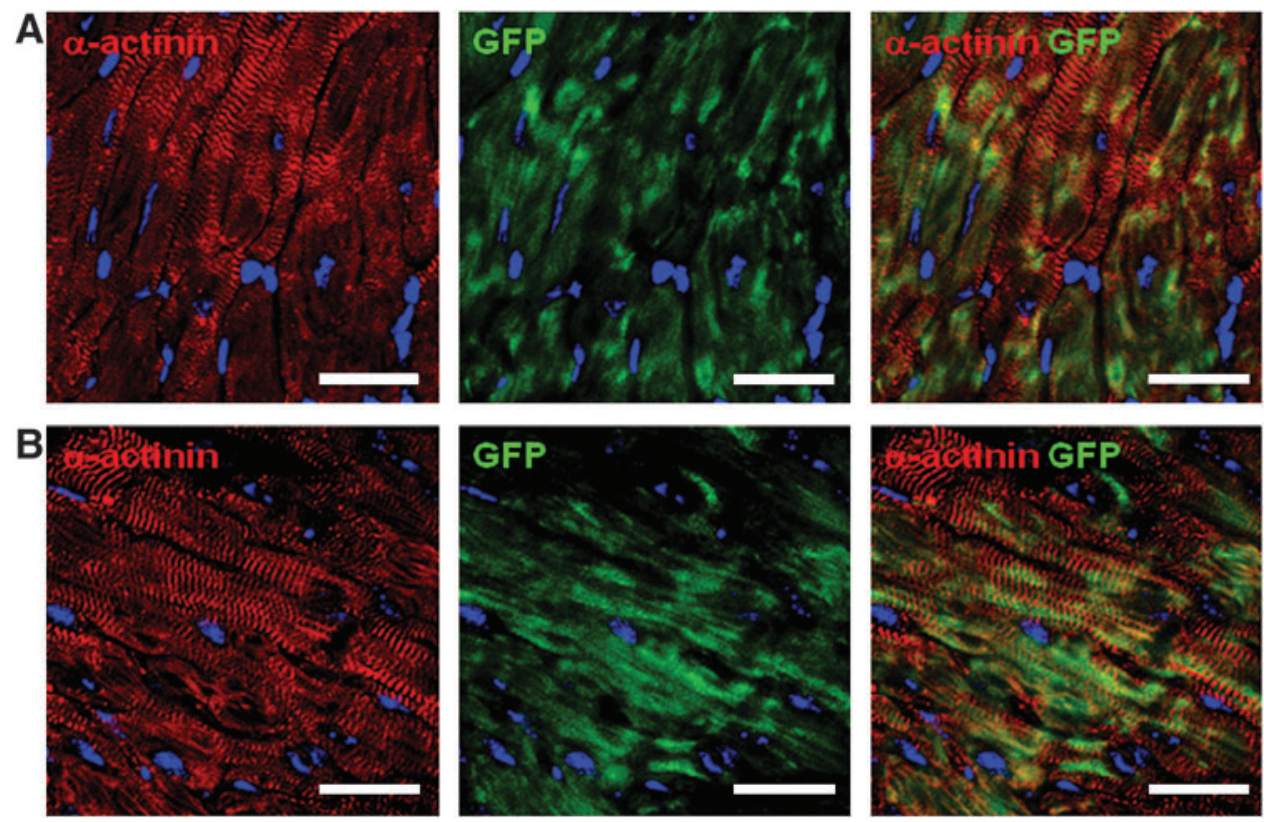

FIG. 6. Cell engraftment in SCID mice heart and cardiogenic differentiation. Confocal images $(0.5 \mu \mathrm{m}$ width) of heart sections of SCID mice at 4 weeks after myocardial injection of CPCs labeled with GFP. (A, B) Heart sections were stained for GFP (green), DAPI (blue), and $\alpha$ actinin (red). Scale bars: $25 \mu \mathrm{m}$. GFP, green fluorescent protein; SCID, severe combined immunodeficiency. 
form of a $\mathrm{Ca}^{2+}$ wave across the entire cell, resulting in a global $\mathrm{Ca}^{2+}$ signal. Figure $4 \mathrm{C}$ shows linescan and line profile of a field-stimulated CPC after 2 weeks of differentiation. Electrical pacing at $0.1 \mathrm{~Hz}$ triggered synchronized global $\mathrm{Ca}^{2+}$ transients across the entire cell, demonstrating that CSC-derived cardiomyocytes present all molecular requirements for functional excitation-contraction (EC)-coupling. In Figure 4D, the $\mathrm{Ca}^{2+}$ signal dynamics of three spatially separated locations in a single cell $(a, b, c)$ are shown in the respective line profiles. Despite a highly synchronized rise of the $\mathrm{Ca}^{2+}$ transient (indicated by the dashed line) in all three regions, indicative of a well-developed EC-coupling mechanism, the $\mathrm{Ca}^{2+}$ signal differed in the maximal amplitude, duration, and decay, consistent with a state of differentiation corresponding to an early developmental stage.

\section{Differentiation into smooth muscle and endothelial cells}

Differentiation into smooth muscle was assessed by analyzing expression levels of smMHC, which was largely upregulated in cultures maintained under differentiation conditions (Fig. 5A). Accordingly, differentiated cells expressing smMHCs were readily detected by immunostaining (Fig. 5B). These cells represented $4 \%$ of the total population, whereas no $\mathrm{smMHC}^{\mathrm{POS}}$ cells were stained in proliferation medium (Fig. 5C). Further, approximately a third of the smMHC ${ }^{\mathrm{POS}}$ cells coexpressed $\alpha$ actinin (Fig. 5B). Expression of CD31 was not stimulated in differentiating cultures (Fig. 5A). Therefore, we did not observe any cells staining positive for CD31 under differentiating conditions. To definitely establish the lack of differentiation potential of CPCs toward the endothelial lineage, CPCs were cultured in an endothelial cell differentiation medium. ${ }^{21}$ Even under these conditions, no endothelial differentiation could be detected (not shown). These findings were confirmed using cells isolated based on mesenchymal marker expression (Supplementary Fig. S6E, F).

\section{Cell engraftment in the mouse heart}

The engraftment, survival, and differentiation capacities of proliferating cells were tested in vivo in transplantation experiments using immunodeficient SCID mice to reduce the risk of graft rejection. To identify the injected cells after transfer into mouse hearts, cells were transduced with a lentivirus expressing GFP under the control of the human PGK promoter. Immunostaining indicated that the GFP ${ }^{\mathrm{POS}}$ cells still expressed Nkx2.5 after lentiviral infection (Supplementary Fig. 7A). Therefore, single-cell suspension was injected at three sites of the left ventricle. Engraftment was analyzed at 1 and 4 weeks postinjection. GFP expression was detected in all transplanted mice at 1 week and in $60 \%$ of the animals at 4 weeks after injection. One week after transfer, some GFP ${ }^{\mathrm{POS}}$ cells retained Nkx2.5 staining (Supplementary Fig. S7B). At that time, engrafted $\mathrm{GFP}^{\mathrm{POS}}$ cells were essentially $\alpha$-actinin negative and similar to the transferred CPCs (Supplementary Fig. S7C). In sharp contrast, GFP ${ }^{\mathrm{POS}} \alpha$-actinin ${ }^{\mathrm{POS}}$ cells were readily detected 4 weeks postinjection using confocal microscopy (Fig. 6 and Supplementary Fig. 8). Nonspecific autofluorescence was eliminated using a window of detection corresponding to the GFP-specific fluorescence emission excluding the autofluorescence emission spectra. ${ }^{31}$ Lower-magnification analysis indicated that $\mathrm{GFP}^{\mathrm{POS}}, \alpha$-actinin ${ }^{\mathrm{POS}}$ cells formed large patches of engrafted cells (Supplementary Fig. S8A, B). Some cells retained Nkx2.5 expression (Supplementary Fig. S8C). Importantly, staining for Cx43 demonstrated the presence of gap junction between human engrafted differentiated cardiomyocytes and the mouse myocardium (Fig. 7).

\section{Discussion}

In this study, we investigated whether the human fetal heart could represent a suitable source of CPCs. At 12 weeks of gestation, most of the ventricular $\alpha$-actinin ${ }^{\text {POS }}$ cardiomyocytes expressed Nkx2.5, suggesting that, at this developmental stage, cardiomyocytes still presented an immature cardiac phenotype. ${ }^{32}$ In the ventricles, $\mathrm{Nkx} 2.5^{\mathrm{POS}}$ cells that
FIG. 7. Connection of engrafted cells to the mouse myocardium. Staining of heart sections from SCID mice at 4 weeks after myocardial injection of CPCs labeled with GFP. (A, B) Heart sections were stained for GFP (green), DAPI (blue), $\alpha$-actinin (red), and Cx43 (white). Arrows indicate the presence of $\mathrm{Cx}-43$ at the intercalated disc between a human and a mouse cell. Scale bars: $25 \mu \mathrm{m}$.
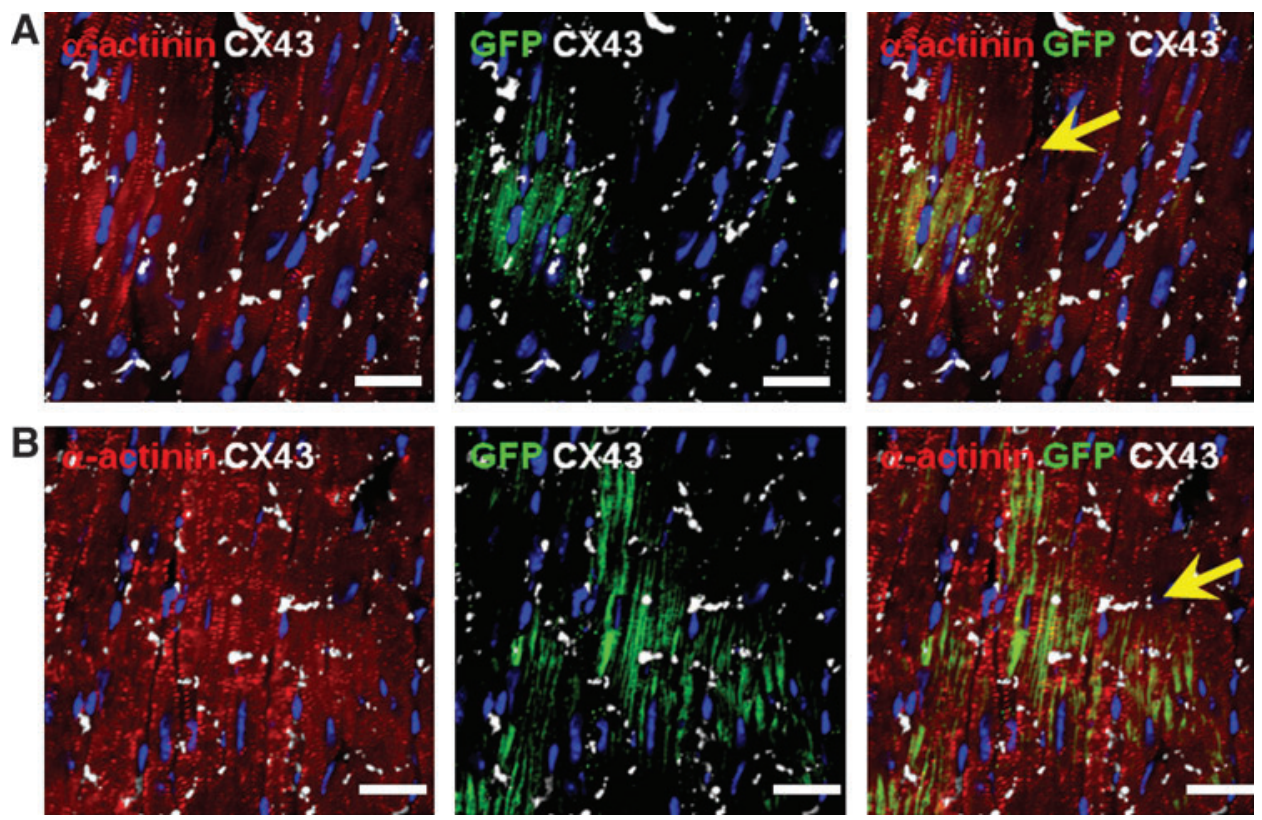
did not express $\alpha$-actinin were hardly detected. However, some $\alpha$-actinin ${ }^{\mathrm{NEG}}, \mathrm{Nkx2.5^{ \textrm {POS } }}$ cells were detected in the atrioventricular ring. Some of these $\mathrm{Nkx} 2.5^{\mathrm{POS}}$ cells coexpressed KDR, but $\mathrm{KDR}^{\mathrm{POS}}$ cells were mostly observed in small myocardial capillaries in the developing ventricles, as previously described. ${ }^{33}$ Finally, cells expressing Isl1, a marker of cells originating in the secondary heart field, which eventually give rise to the outflow tract, ${ }^{12,34}$ were identified in the vicinity of the aorta and pulmonary arteries. ${ }^{13}$ These cells are reminiscent of the recently described $\mathrm{Isl}^{\mathrm{POS}}$ cells present in the atrial septum of the postnatal human heart. ${ }^{12,13}$ We next isolated a cell population from the ventricles of human fetal hearts. These cells did not significantly express late cardiac markers $\alpha$-MHC, $\beta$-MHC, or troponin I and were also negative for $\alpha$-actinin staining. Further, we could not detect any expression of smooth muscle, endothelial, and hematopoietic markers. In contrast, isolated cells expressed early cardiac markers Gata4, Mef2c, and Nkx2.5. We consider that, therefore, these cells represent precursors committed to the cardiogenic lineage. The vast majority of

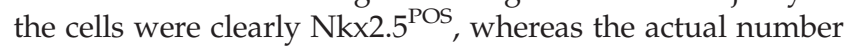
of cells demonstrating significant Isl1 or KDR staining in vitro was very low. Cultured $\mathrm{Nkx} 2.5^{\mathrm{POS}}$ cells expressed the proliferation marker Ki67 and could be expanded in vitro. Differentiation into $\alpha$-actinin ${ }^{\mathrm{POS}}$ cardiomyocytes could be easily obtained. Interestingly, a significant amount of SMCs were produced upon induction of differentiation, but no endothelial cells. Some $\alpha$-actinin ${ }^{\text {POS }}$ cells also stained for smMHC, representing intermediate state in the maturation process. All together these data indicate that precursors

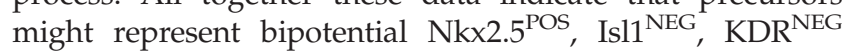
precursors, common to the cardiogenic and smooth muscle lineages. Moreover, it has been recently published that in the mouse the decision to enter either the cardiac or the SMC program is made at the level of precursors expressing Nkx2.5. ${ }^{11,14}$ On the functional level, differentiated CPCs presented a variety of spontaneous and triggered calcium signals. Importantly, with increasing degree of differentiation, CPC-derived myocytes showed consistent responsiveness to electrical stimulation followed by rapidly rising and subcellularly synchronized $\mathrm{Ca}^{2+}$ transients, which are indicative of a reliable functional EC-coupling mechanism. These findings are consistent with the observed expression of Cx43 on engrafted human cardiomyocytes, indicating that electromechanical coupling takes place between the CPCderived cells and the endogenous mouse myocardium.

Several groups have isolated CPCs from developing, postnatal, and adult heart samples based on various protocols. ${ }^{5,6,9,11,12,14,21-27}$ In some instances, isolation of CPCs relied on surface markers that are expressed on hematopoietic stem cells, such as c-kit and Sca-1. Therefore, c-kit ${ }^{\mathrm{POS}} \mathrm{CPCs}$ have been identified in the rat adult heart. These cells were reported to be clonogenic and able to differentiate into cardiomyocytes, SMCs, and endothelial cells. ${ }^{5}$ Similarly, c-kit ${ }^{\mathrm{POS}}$ cardiac progenitors were isolated from human adult ventricles. These Nkx2.5 ${ }^{\mathrm{NEG}}$ cells were able to give rise to the three main cardiac lineages (cardiomyocytes, endothelial cells, and SMCs) in vitro and in vivo. ${ }^{25}$ In other studies, CPCs, which grew in self-adherent clusters named cardiospheres, were isolated from subcultures of postnatal human biopsies. These mixed populations expressing c-kit, CD31, CD34, and KDR were claimed to represent a source of cardiomyocyte precur-


did not appear to express c-kit or endothelial markers. It is, therefore, likely that they represent a different precursor population or a different stage in the cardiogenic differentiation pathway.

Using a similar approach, Sca- $1^{\mathrm{POS}}$ cells that could differentiate into cardiomyocytes were isolated from the adult mouse heart. ${ }^{6}$ Our own data suggested the presence of Sca$1^{\mathrm{POS}} \mathrm{CPCs}$ in the neonatal mouse heart. ${ }^{26}$ Further, a cardiac side-population isolated by FACS according to Hoechst dye exclusion, and expressing Sca-1, was also shown to produce differentiated cardiomyocytes. ${ }^{8,9}$ This stem cell marker could represent a suitable marker for the identification and purification of CPCs. However, the ortholog of the mouse ly $6 \mathrm{~A} / \mathrm{E}$ gene does not exist in humans. Nevertheless, a recent report described human cardiac precursors isolated from the fetal heart based on the capacity of antibodies directed against the mouse Sca-1 protein to bind to an unknown cell surface protein. These cells expressed Isl1 and CD31, and a significant percentage also expressed c-kit. Under differentiation conditions, these precursors gave rise to cardiomyocytes, SMCs, and endothelial cells in vitro and in vivo. ${ }^{27-29}$ It is,

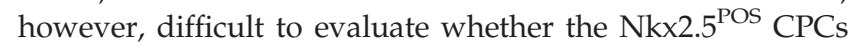
described herein correspond to a distinct or an identical precursor population. On the one hand, both fetal precursor populations could differentiate into cardiomyocytes and SMCs and might then represent common precursors to these two cardiovascular lineages. On the other hand, these two CPC populations can be distinguished based on different profiles of marker expression. Indeed, the CPCs described in the present article were negative for c-Kit and CD31. Further, these cells were not recognized by antibodies directed against the mouse Sca- 1 antigen. Finally, they were not able to produce endothelial cells. All together, these data suggest that the two populations might be representative of distinct intermediates within the cardiac precursor population in the developing human heart. Interestingly, a cardiac population identified based on the expression of the mesenchymal markers CD73, CD90, and CD105 contained cardiogenic precursors, suggesting that these surface markers could be used to isolate precursors from human cardiac biopsies.

In a series of experiments in the mouse, cardiovascular progenitor cells expressing the transcription factors Nkx2.5 and Isl1 as well as Flk-1 were identified in the postnatal heart and shown to contribute to the cardiomyocyte, the smooth muscle, and the endothelial cell lineages. ${ }^{12,14}$ According to the proposed cellular hierarchy, Isl1 is downregulated as soon as the cell enters the differentiation program. Therefore,


pressed Nkx2.5 and Isl-1 only and, at a later stage, produced

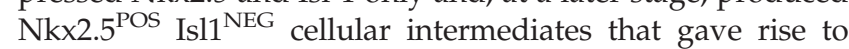
cardiomyocytes and SMCs. ${ }^{14}$ In a parallel study and in accordance with these findings, Nkx2.5 ${ }^{\mathrm{POS}}$ myocardial and vascular smooth muscle precursors were isolated from the developing mouse heart. ${ }^{11}$ As our study identifies a population of Nkx2.5 ${ }^{\mathrm{POS}}$, Is11 ${ }^{\mathrm{NEG}} \mathrm{KDR}$ (Flk-1) ${ }^{\mathrm{NEG}}$ fetal precursors, which are able to generate cardiomyocytes and SMCs, it is likely that these cells represent human equivalents of the bipotential precursors described in the mouse. This is also supported by the fact that differentiating Nkx2.5 $5^{\mathrm{POS}}$ CPCs described herein produced cells expressing both $\alpha$-actinin and smMHC. Interestingly, $\mathrm{KDR}^{\mathrm{LOW}} \mathrm{c}^{-\mathrm{kit}^{\mathrm{NEG}}}$ human 
cardiovascular precursors obtained after induction of differentiation in ES cells generated intermediate cells coexpressing cardiac troponin $\mathrm{T}$ and SMA and ultimately cardiomyocytes and SMCs. ${ }^{19}$

When injected into the mouse heart, $\mathrm{Nkx} 2.5^{\mathrm{POS}} \mathrm{CPC}$ s were able to engraft, survive, and maintain their cardiac commitment in vivo. At 1 week after transfer, the injected cells were detected as undifferentiated $\left(\mathrm{Nk} \times 2.5^{\mathrm{POS}}, \alpha\right.$-actinin $\left.{ }^{\mathrm{NEG}}\right)$ precursors. In contrast, these cells differentiated into $\alpha$-actininexpressing cardiomyocytes at 4 weeks after injection into the myocardium. Similar to what has been observed in vitro, human CPC-derived cardiomyocytes demonstrated organized sarcomeres in the mouse heart. Several patches of engrafted $\mathrm{GFP}^{\mathrm{POS}}, \alpha$-actinin ${ }^{\mathrm{POS}}$ cells were detected in different areas of the ventricles, indicating that engrafted cells were not solely located at the sites of injection. This suggests that the injected cells exhibited some capacity to invade the host myocardium. Because of the low numbers of human cells found in ventricles, precursor engraftment is unlikely to produce significant improvement of function in a damaged heart. Nevertheless, these data confirmed that human fetal heart-derived progenitors have the potential to generate a new myocardium that is structurally coupled to the host myocardium. Interestingly, the isolated cells appear already committed to the cardiovascular lineages, although retaining a proliferative capacity that allows amplification in vitro. Provided that these cells would be sufficiently amplified in culture and significant amounts can be implanted in the heart, they may represent a suitable source of precursors for cell therapies of heart diseases in humans.

\section{Acknowledgments}

The authors thank Dr. Mohamed Nemir for critical reading of the manuscript. Sandy Ogay and Nathalie Demcik are thanked for their technical assistance. The authors also thank Dr. Marie-Claire Osterheld for sharing with us her expertise in human fetal anatomy and Estelle Devevre for technical help with flow cytometry. This work was supported in part by grants from the Swiss National Science Foundation (grants 33CM30-124090 and 31003A-127590 to T.P.; grant 31109693 to E.N.) and CardioMet: Center for Cardiovascular and Metabolic Diseases, University of Lausanne Medical School, Lausanne, Switzerland (to C.G.).

\section{Disclosure Statement}

No competing financial interests exist.

\section{References}

1. Passier, R., van Laake, L.W., and Mummery, C.L. Stem-cellbased therapy and lessons from the heart. Nature 453, 322, 2008

2. Gonzales, C., and Pedrazzini, T. Progenitor cell therapy for heart disease. Exp Cell Res 315, 3077, 2009.

3. Anversa, P., and Nadal-Ginard, B. Myocyte renewal and ventricular remodelling. Nature 415, 240, 2002.

4. Kajstura, J., Urbanek, K., Perl, S., Hosoda, T., Zheng, H., Ogorek, B., Ferreira-Martins, J., Goichberg, P., RondonClavo, C., Sanada, F., D'Amario, D., Rota, M., Del, M.F., Orlic, D., Tisdale, J., Leri, A., and Anversa, P. Cardiomyogenesis in the adult human heart. Circ Res 107, 305, 2010.

5. Beltrami, A.P., Barlucchi, L., Torella, D., Baker, M., Limana, F., Chimenti, S., Kasahara, H., Rota, M., Musso, E., Urbanek,
K., Leri, A., Kajstura, J., Nadal-Ginard, B., and Anversa, P. Adult cardiac stem cells are multipotent and support myocardial regeneration. Cell 114, 763, 2003.

6. Oh, H., Bradfute, S.B., Gallardo, T.D., Nakamura, T., Gaussin, V., Mishina, Y., Pocius, J., Michael, L.H., Behringer, R.R., Garry, D.J., Entman, M.L., and Schneider, M.D. Cardiac progenitor cells from adult myocardium: homing, differentiation, and fusion after infarction. Proc Natl Acad Sci U S A 100, 12313, 2003.

7. Hierlihy, A.M., Seale, P., Lobe, C.G., Rudnicki, M.A., and Megeney, L.A. The post-natal heart contains a myocardial stem cell population. FEBS Lett 530, 239, 2002.

8. Martin, C.M., Meeson, A.P., Robertson, S.M., Hawke, T.J., Richardson, J.A., Bates, S., Goetsch, S.C., Gallardo, T.D., and Garry, D.J. Persistent expression of the ATP-binding cassette transporter, Abcg2, identifies cardiac SP cells in the developing and adult heart. Dev Biol 265, 262, 2004.

9. Pfister, O., Mouquet, F., Jain, M., Summer, R., Helmes, M., Fine, A., Colucci, W.S., and Liao, R. CD31- but Not CD31+ cardiac side population cells exhibit functional cardiomyogenic differentiation. Circ Res 97, 52, 2005.

10. Chien, K.R., Domian, I.J., and Parker, K.K. Cardiogenesis and the complex biology of regenerative cardiovascular medicine. Science 322, 1494, 2008.

11. Wu, S.M., Fujiwara, Y., Cibulsky, S.M., Clapham, D.E., Lien, C.L., Schultheiss, T.M., and Orkin, S.H. Developmental origin of a bipotential myocardial and smooth muscle cell precursor in the mammalian heart. Cell 127, 1137, 2006.

12. Laugwitz, K.L., Moretti, A., Lam, J., Gruber, P., Chen, Y., Woodard, S., Lin, L.Z., Cai, C.L., Lu, M.M., Reth, M., Platoshyn, O., Yuan, J.X., Evans, S., and Chien, K.R. Postnatal isl1 + cardioblasts enter fully differentiated cardiomyocyte lineages. Nature 433, 647, 2005.

13. Bu, L., Jiang, X., Martin-Puig, S., Caron, L., Zhu, S., Shao, Y., Roberts, D.J., Huang, P.L., Domian, I.J., and Chien, K.R. Human ISL1 heart progenitors generate diverse multipotent cardiovascular cell lineages. Nature 460, 113, 2009.

14. Moretti, A., Caron, L., Nakano, A., Lam, J.T., Bernshausen, A., Chen, Y., Qyang, Y., Bu, L., Sasaki, M., Martin-Puig, S., Sun, Y., Evans, S.M., Laugwitz, K.L., and Chien, K.R. Multipotent embryonic isl1 + progenitor cells lead to cardiac, smooth muscle, and endothelial cell diversification. Cell 127, 1151, 2006.

15. Motoike, T., Markham, D.W., Rossant, J., and Sato, T.N. Evidence for novel fate of Flk1 + progenitor: contribution to muscle lineage. Genesis 35, 153, 2003.

16. Ema, M., Takahashi, S., and Rossant, J. Deletion of the selection cassette, but not cis-acting elements, in targeted Flk1-lacZ allele reveals Flk1 expression in multipotent mesodermal progenitors. Blood 107, 111, 2006.

17. Kattman, S.J., Huber, T.L., and Keller, G.M. Multipotent flk$1+$ cardiovascular progenitor cells give rise to the cardiomyocyte, endothelial, and vascular smooth muscle lineages. Dev Cell 11, 723, 2006.

18. Christoforou, N., Miller, R.A., Hill, C.M., Jie, C.C., McCallion, A.S., and Gearhart, J.D. Mouse ES cell-derived cardiac precursor cells are multipotent and facilitate identification of novel cardiac genes. J Clin Invest 118, 894, 2008.

19. Yang, L., Soonpaa, M.H., Adler, E.D., Roepke, T.K., Kattman, S.J., Kennedy, M., Henckaerts, E., Bonham, K., Abbott, G.W., Linden, R.M., Field, L.J., and Keller, G.M. Human cardiovascular progenitor cells develop from a KDR+ embryonic-stem-cell-derived population. Nature 453, 524, 2008. 
20. Leschik, J., Stefanovic, S., Brinon, B., and Puceat, M. Cardiac commitment of primate embryonic stem cells. Nat Protoc 3, 1381, 2008.

21. Ott, H.C., Matthiesen, T.S., Brechtken, J., Grindle, S., Goh, S.K., Nelson, W., and Taylor, D.A. The adult human heart as a source for stem cells: repair strategies with embryonic-like progenitor cells. Nat Clin Pract Cardiovasc Med 4 Suppl 1, S27-S39, 2007.

22. Messina, E., De, A.L., Frati, G., Morrone, S., Chimenti, S., Fiordaliso, F., Salio, M., Battaglia, M., Latronico, M.V., Coletta, M., Vivarelli, E., Frati, L., Cossu, G., and Giacomello, A. Isolation and expansion of adult cardiac stem cells from human and murine heart. Circ Res 95, 911, 2004.

23. Smith, R.R., Barile, L., Cho, H.C., Leppo, M.K., Hare, J.M., Messina, E., Giacomello, A., Abraham, M.R., and Marban, E. Regenerative potential of cardiosphere-derived cells expanded from percutaneous endomyocardial biopsy specimens. Circulation 115, 896, 2007.

24. Rota, M., Padin-Iruegas, M.E., Misao, Y., De, A.A., Maestroni, S., Ferreira-Martins, J., Fiumana, E., Rastaldo, R., Arcarese, M.L., Mitchell, T.S., Boni, A., Bolli, R., Urbanek, K., Hosoda, T., Anversa, P., Leri, A., and Kajstura, J. Local activation or implantation of cardiac progenitor cells rescues scarred infarcted myocardium improving cardiac function. Circ Res 103, 107, 2008.

25. Bearzi, C., Rota, M., Hosoda, T., Tillmanns, J., Nascimbene, A., De, A.A., Yasuzawa-Amano, S., Trofimova, I., Siggins, R.W., Lecapitaine, N., Cascapera, S., Beltrami, A.P., D'Alessandro, D.A., Zias, E., Quaini, F., Urbanek, K., Michler, R.E., Bolli, R., Kajstura, J., Leri, A., et al. Human cardiac stem cells. Proc Natl Acad Sci U S A 104, 14068, 2007.

26. Rosenblatt-Velin, N., Lepore, M.G., Cartoni, C., Beermann, F., and Pedrazzini, T. FGF-2 controls the differentiation of resident cardiac precursors into functional cardiomyocytes. J Clin Invest 115, 1724, 2005.

27. Goumans, M.J., de Boer, T.P., Smits, A.M., van Laake, L.W., van Vliet, P., Metz, C.H.G., Korfage, T.H., Kats, K.P., Hochstenbach, R., Pasterkamp, G., Verhaar, M.C., van der Heyden, M.A.G., de Kleijn, D., Mummery, C.L., van Veen, T.A.B., Sluijter, J.P.G., and Doevendans, P.A. TGF-[beta]1 induces efficient differentiation of human cardiomyocyte progenitor cells into functional cardiomyocytes in vitro. Stem Cell Research 1, 138, 2008.

28. Smits, A.M., van Laake, L.W., den, O.K., Schreurs, C., Szuhai, K., van Echteld, C.J., Mummery, C.L., Doevendans, P.A., and Goumans, M.J. Human cardiomyocyte progenitor cell transplantation preserves long-term function of the infarcted mouse myocardium. Cardiovasc Res 83, 527, 2009.

29. de Boer, T.P., van Veen, T.A., Jonsson, M.K., Kok, B.G., Metz, C.H., Sluijter, J.P., Doevendans, P.A., de Bakker, J.M., Goumans, M.J., and van der Heyden, M.A. Human cardiomyocyte progenitor cell-derived cardiomyocytes display a maturated electrical phenotype. J Mol Cell Cardiol 48, 254, 2010.

30. Wessels, A., Markman, M.W., Vermeulen, J.L., Anderson, R.H., Moorman, A.F., and Lamers, W.H. The development of the atrioventricular junction in the human heart. Circ Res 78, 110, 1996.

31. van Laake, L.W., Passier, R., Monshouwer-Kloots, J., Verkleij, A.J., Lips, D.J., Freund, C., den, O.K., Ward-van, O.D., Korving, J., Tertoolen, L.G., van Echteld, C.J., Doevendans, P.A., and Mummery, C.L. Human embryonic stem cellderived cardiomyocytes survive and mature in the mouse heart and transiently improve function after myocardial infarction. Stem Cell Res 1, 9, 2007.

32. Thomas, P.S., Kasahara, H., Edmonson, A.M., Izumo, S., Yacoub, M.H., Barton, P.J., and Gourdie, R.G. Elevated expression of Nkx-2.5 in developing myocardial conduction cells. Anat Rec 263, 307, 2001.

33. Kaipainen, A., Korhonen, J., Pajusola, K., Aprelikova, O., Persico, M.G., Terman, B.I., and Alitalo, K. The related FLT4, FLT1, and KDR receptor tyrosine kinases show distinct expression patterns in human fetal endothelial cells. J Exp Med 178, 2077, 1993.

34. Cai, C.L., Liang, X., Shi, Y., Chu, P.H., Pfaff, S.L., Chen, J., and Evans, S. Isl1 identifies a cardiac progenitor population that proliferates prior to differentiation and contributes a majority of cells to the heart. Dev Cell 5, 877, 2003.

Address correspondence to: Thierry Pedrazzini, Ph.D.

Experimental Cardiology Unit Department of Medicine University of Lausanne Medical School CH-1011 Lausanne Switzerland

E-mail: thierry.pedrazzini@chuv.ch

Received: January 11, 2011

Accepted: August 18, 2011

Online Publication Date: September 26, 2011 